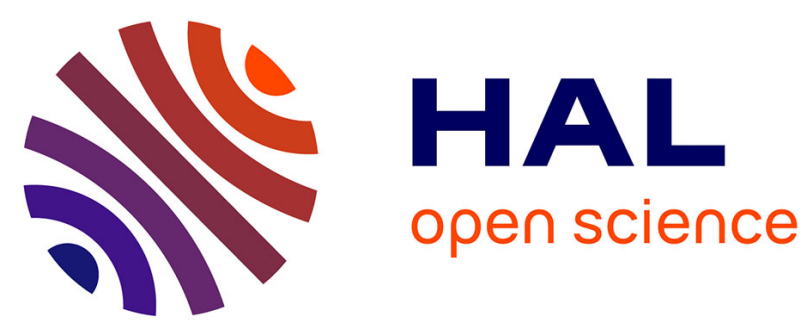

\title{
Observation of entrainment at the interface between monsoon flow and the Saharan Air Layer
}

Guylaine Canut, Marie Lothon, Frédérique Saïd, Fabienne Lohou

\section{To cite this version:}

Guylaine Canut, Marie Lothon, Frédérique Saïd, Fabienne Lohou. Observation of entrainment at the interface between monsoon flow and the Saharan Air Layer. Quarterly Journal of the Royal Meteorological Society, 2010, 136 (S1), pp.34-46. 10.1002/qj.471 . hal-00986902

\section{HAL Id: hal-00986902 https://hal.science/hal-00986902}

Submitted on 18 Aug 2021

HAL is a multi-disciplinary open access archive for the deposit and dissemination of scientific research documents, whether they are published or not. The documents may come from teaching and research institutions in France or abroad, or from public or private research centers.
L'archive ouverte pluridisciplinaire HAL, est destinée au dépôt et à la diffusion de documents scientifiques de niveau recherche, publiés ou non, émanant des établissements d'enseignement et de recherche français ou étrangers, des laboratoires publics ou privés. 


\title{
Observation of entrainment at the interface between monsoon flow and the Saharan Air Layer
}

\author{
G. Canut,* M. Lothon, F. Saïd and F. Lohou \\ Université de Toulouse/CNRS UMR-5560, Laboratoire d'Aérologie, Toulouse, France
}

\begin{abstract}
During the AMMA experiment, the French ATR aircraft flew in the lower troposphere in south Niger, with instruments that allow fast measurement of wind, temperature and humidity. Stacked legs flown between early June and mid-August into the moist southwesterly monsoon flow and the dry northeasterly flow of the Saharan Air Layer (SAL) above, enable us to study the interaction between the two flows at the turbulence scale and the role of the planetary boundary layer (PBL) in the transfers between them. We describe the fluctuations observed at the top of the PBL and their evolution during the season. Dry tongues approximately $600 \mathrm{~m}$ wide and a few kilometres apart, intruding from the overlying SAL down into the PBL, are characteristic of the Sahelian region at that time of year. They are fully part of the entrainment process at the PBL top and responsible for large moisture fluxes in the upper PBL. They also skew the water vapour distribution which in turn impacts the water vapour scales. We evaluate the impact of the entrainment by use of a conditional analysis on combined fluctuations. The dry tongues play the largest role down to two thirds of the PBL depth. We find larger entrainment during early monsoon than during its active phase, and a large variability of the ratio of entrainment buoyancy flux over surface flux.
\end{abstract}

KEY WORDS AMMA; atmospheric boundary layer; West African monsoon; dry tongues

\section{Introduction}

Although generated and governed on a global scale, the West African monsoon (WAM) shows a very striking diurnal cycle through most of its components (Peyrillé, 2005; Parker et al., 2005): for example the heat low (HL) in the Saharan desert (Lavaysse et al., 2009) and the Intertropical Discontinuity (ITD) - the lower interface between the moist southwesterly monsoon flow and the dry Saharan air - (Lothon et al., 2008). Figure 1 shows a sketch of the main components of the WAM. Another important component of the middle troposphere is the African Easterly Jet, found at about $500 \mathrm{hPa}$ in approximate thermal wind balance, and produced by the temperature and moisture contrast between the Sahara to the north and the Gulf of Guinea to the south (Burpee, 1972; Cook, 1999). The AEJ also shows a pronounced diurnal cycle (Lee et al., 2007; Kalapureddy et al., 2009) in addition to 3-4-day propagating disturbances, known as African Easterly Waves (AEW) (Burpee, 1972).

The signature of the diurnal cycle in several key components of the WAM is due to the important role played by surface-atmosphere interactions within the WAM system and the very large contrasts of surface moisture and albedo from the north of the region to the south. As an interface between the surface and the free atmosphere, the planetary boundary layer (PBL) is

\footnotetext{
*Correspondence to: G. Canut, Centre de Recherches Atmosphériques, 8 route de Lannemezan, 65300 Campistrous, France. cang@aero.obs-mip.fr
}

inherently involved in the processes of the WAM diurnal cycle. The Sahel is of special interest in the context of the WAM, because of its sensitivity to a wide range of factors - from climate, hydrology, agriculture to economy, health and sociology - due to its location at the transition between vegetated areas to the south and the desert to the north.

The diurnal oscillation of the low troposphere in this area is manifested by a low-level jet at night and a deep PBL during the day throughout most of the year (Parker et al., 2005; Lothon et al., 2008). The turbulent PBL mixing appears to play a very large role in the daytime southward migration of the ITD. However, during the wettest months, both the dry convection and nocturnal jet are weakened, and deep convection takes place instead.

There is a need for a better understanding of the transfers of water vapour from, to and within the lower troposphere. Large-scale dry intrusions from midlatitudes at about $500 \mathrm{hPa}$, which is the height of the top of the Saharan Air Layer (SAL), are known to interact with deep convection (Roca et al., 2005) but also, before deep convection, to inhibit the moistening of the low troposphere by bringing dry air down to lower layers. Meanwhile, advection associated with the monsoon flow tends to moisten the low troposphere. Small-scale processes are significantly involved in these vertical and horizontal processes, and in the diurnal cycle mentioned above, particularly entrainment at the PBL top. Their role in the transport of water vapour in the general and larger-scale context of the WAM needs further clarification. 


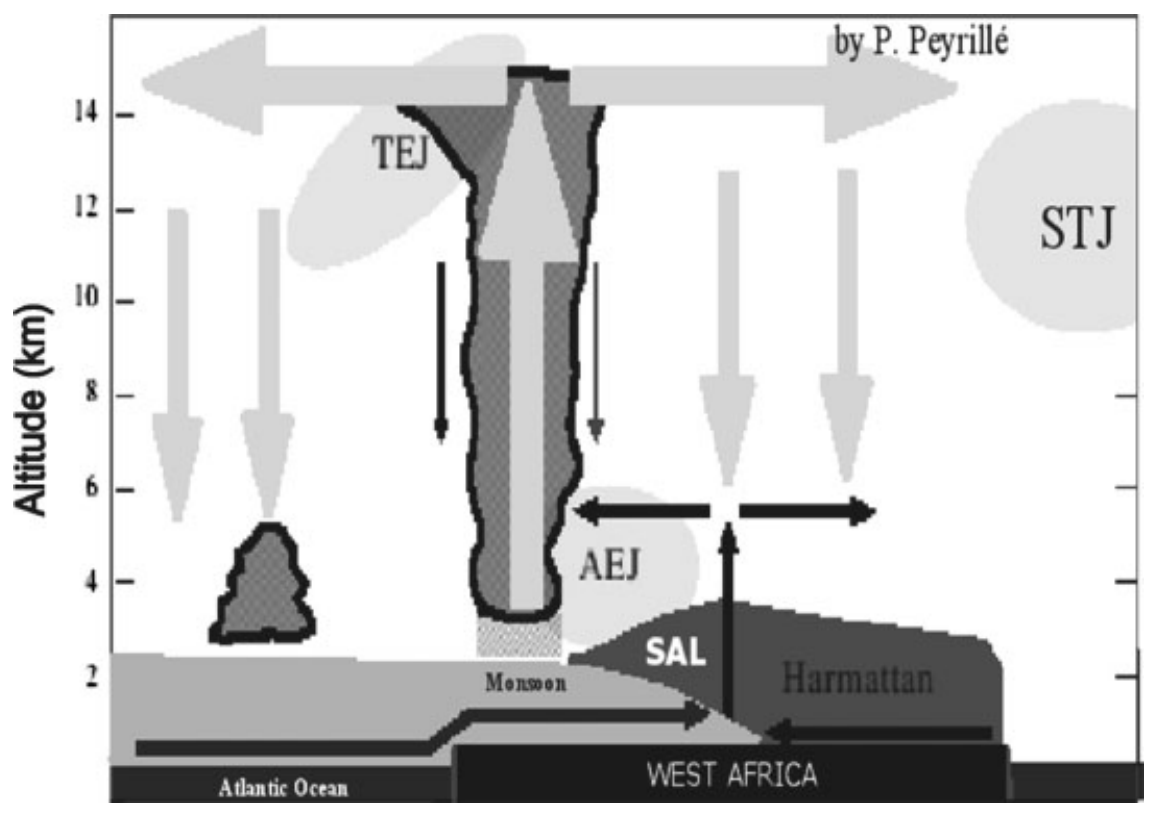

Figure 1. 2D schematic view of the West African monsoon system, after Peyrille (2005). SAL = Saharan Air Layer; AEJ = African Easterly Jet; TEJ = Tropical Easterly Jet; STJ = SubTropical Jet. ITD is the surface interface between the monsoon flow and the SAL (Inter Tropical Discontinuity).

Previous studies, especially those conducted on the stratocumulus-topped boundary layer (e.g. Lilly, 1968; Stevens, 2002; Stevens et al., 2003), have shown that entrainment can play a major role in the variability of cloud depth and spatial extension and structure, over large areas (several hundreds and even thousands of kilometres), although it is a very small-scale (a few hundred metres) process. One can expect entrainment to play a significant role in the WAM based on the large amplitude of its diurnal cycle, the magnitude of surfaceatmosphere interactions and the large area over which the PBL/SAL interface extends.

We use here high-rate measurements made by the French ATR aircraft during the AMMA (African Monsoon Multidisciplinary Analysis) Special Observation Periods (SOP) that took place during the summer (wet season) of 2006 (Redelsperger et al., 2006). We consider 15 flights between early June, when the monsoon is setting in, and mid-August, when it is in its active phase. During this period, the monsoon flow supplies moisture to the low layers via advection from the south. This humidity is redistributed vertically during the day by turbulence. Lothon et al. (2008) studied this cycle statistically from nocturnal advection to diurnal vertical mixing using radiosounding and Ultra-High Frequency (UHF) wind profiler measurements made continuously during the 2006 AMMA EOP (Enhanced Observing Period). Part of the observed drying is due to encroachment (Garratt, 1992) and part can be attributed to entrainment of dry air from the free troposphere above. The free troposphere above often corresponds to the much drier air of the closeto-neutral SAL, especially in the beginning of the wet season. PBL turbulent processes thus favour exchanges between the monsoon and the SAL. We therefore focus on the nature of the exchanges between both air masses through the PBL, small-scale process of entrainment and its evolution during the course of the wet season.

Section 2 describes our experimental dataset. In section 3 , we show how dry tongues - which are entirely part of the entrainment process - impact the vertical structure of the PBL. In section 4, we provide estimates of entrainment and discuss its evolution as the monsoon sets in. We also offer a preliminary examination of its connection to the large-scale context.

\section{Experimental data and boundary-layer mean structure}

In Figure 2, the water vapour mixing ratio observed at the ground in Niamey $\left(13^{\circ} 29^{\prime} \mathrm{N}, 2^{\circ} 10^{\prime} \mathrm{E}, 205 \mathrm{~m}\right.$ a.s.l. $)$ during the entire year 2006 shows how marked the seasonal cycle is in this area, with very dry air from November to mid April, followed by moistening for two to three months before a relatively short wet season in August and September and a short drying transition in October. During the dry season as observed in Niamey, the ITD is to the south of the area and the wind at the surface is northeasterly (the so-called 'harmattan'). The moistening transition starts when the ITD has crossed the area during its migration northward. The wind at ground level can be either the monsoon - which progressively moistens the low troposphere - or the harmattan (usually during the day, in the first part of that period). The abrupt meridional shift of the Intertropical Convergence Zone (ITCZ) observed by Sultan and Janicot (2000) indicates the beginning of the active phase of the monsoon. At that point, the water vapour mixing ratio in Niamey is at its maximum and constant.

The early, intermediate and active monsoon phases indicated by the shaded areas in Figure 2 correspond to 


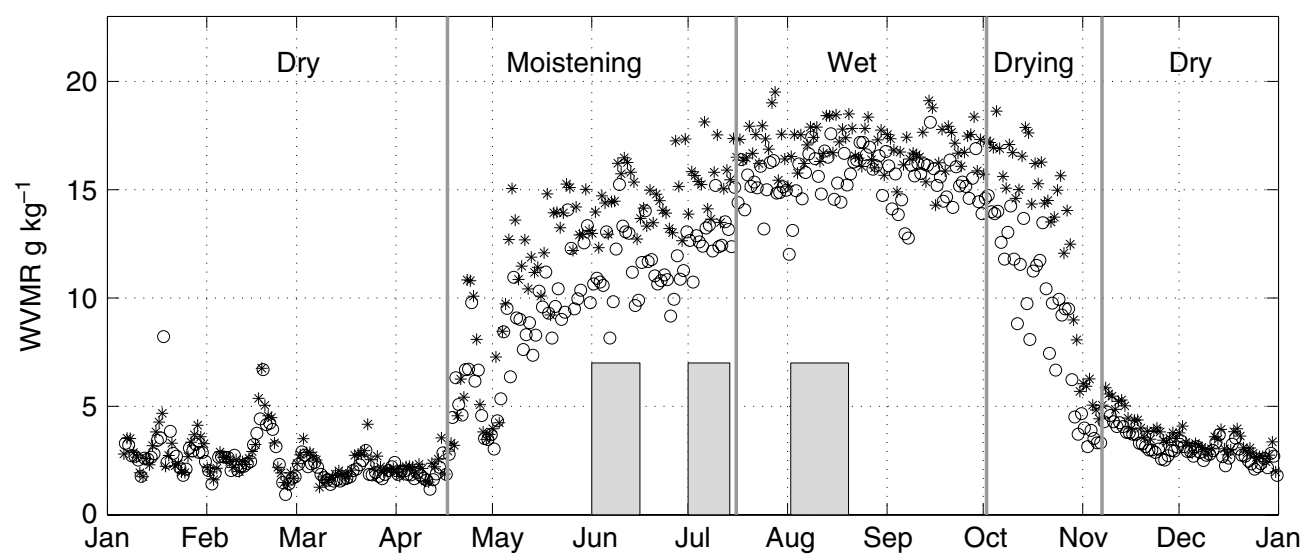

Figure 2. Night-time $(*)$ and daytime $(\circ)$ averaged water vapour mixing ratio measured at the surface at Niamey airport in 2006 . The shaded areas show the three aircraft observation periods (after Lothon et al., 2008).

the three SOPs when the ATR research aircraft flew in the low and mid-troposphere. During all these periods, the ITD is located north of Niamey so that the lowest part of the troposphere is most often occupied by the monsoon flow.

The ATR-42 aircraft flew intensively in the vicinity of Niamey, with instruments that allow fast measurement of wind, temperature and humidity. Details about the instrumentation are provided in Saïd et al. (2009). Eight flights made during the pre- and intermediate monsoon phase (shaded in Figure 2), from early June to mid-July and seven flights made during the active phase of the monsoon between early August and mid-August (third shaded area) are considered in our analysis. Both the preand intermediate monsoon phases are included in what we hereafter call the 'early' monsoon phase.

The flight area was situated about $50 \mathrm{~km}$ away from Niamey Airport. Flying area and strategy are described in Saïd et al. (2009). This area was centred on Banizoumbou, an instrumented ground site that was surveyed several times during the flights. The eight flights undertaken during the early monsoon phase were made over Banizoumbou. Subsequently, during the active monsoon phase, the flight path depended on the forecast location of the convective systems and/or the location of prior rainfall. We selected only flights that took place less than $100 \mathrm{~km}$ from Niamey.

Legs of length 60 to $80 \mathrm{~km}$ were flown during daytime within and above the PBL, i.e. both into the moist southwesterly monsoon flow and the dry easterly flow of the SAL aloft, and sometimes in the shear layer in between.

We applied a $5 \mathrm{~km}$ filter to the $25 \mathrm{~Hz}$ time series to correct for mesoscale variability, which cannot be sampled correctly and thus introduces errors into the calculation of fluxes. The turbulent moments were calculated in 5to 7.5 -minute segments ( 30 to $45 \mathrm{~km}$ length), and both random and systematic errors were estimated (Lenschow et al., 1994). The spread of our estimated fluxes was reduced with the filter, but led to a systematic error that we took into account with a correction based on the cutoff length of the filter and on PBL depth estimates (Saïd et al., 2009).
We hereafter denote $u^{\prime}, v^{\prime}, w^{\prime}, \theta^{\prime}$ and $r_{\mathrm{v}}^{\prime}$ the fluctuations in longitudinal wind, transverse wind, vertical wind, potential temperature and water vapour mixing ratio respectively.

Table I summarizes the PBL characteristics during each flight, as well as some results discussed later in the text. The PBL depth $Z_{\mathrm{i}}$ - taken here as the top of the mixed layer - and an estimate of its linear evolution with time are obtained for each flight. $\partial Z_{\mathrm{i}} / \partial t$ is obtained from two estimates of $Z_{i}$, spaced approximately one hour apart: one is from the vertical sounding of the aircraft and the other from the time when the aircraft once again crosses the PBL during the descending portion of its vertical exploration with stacked legs. $Z_{i}$ is then linearly extrapolated for each leg for our analysis of normalized fluxes and estimates of entrainment at the top. An overline in Table I indicates the average over the duration of the vertical exploration. The mean wind $\bar{U}$, potential temperature $\bar{\theta}$ and water vapour mixing ratio $\bar{r}_{\mathrm{v}}$ in the PBL are obtained from the legs flown below $Z_{i}$. The convective velocity,

$$
w_{*}=\left(\frac{g \overline{w \theta_{\mathrm{v}}} Z_{\mathrm{i}}}{\overline{\theta_{\mathrm{v}}}}\right)^{1 / 3},
$$

is calculated using the buoyancy flux estimates from aircraft measurements, extrapolated to the surface. The jumps across the inversion $\Delta U, \Delta \theta_{\mathrm{v}}$ and $\Delta r_{\mathrm{v}}$ in wind, virtual potential temperature and water vapour content respectively are estimated with the sounding flown before and/or after the stacked legs, based on a first-order-jump approximation of the scalar profiles (Kim et al., 2006). Those jumps characterize the strength of the inversion at the PBL top. They can be quite large between the moist monsoon and the dry SAL which have opposite characteristics. They are assumed to be constant during the flight, which is unlikely, but their variation with time is impossible to estimate with sufficient accuracy. $\gamma$ is the vertical gradient of $\theta_{\mathrm{v}}$ in the free troposphere (the lower part of the SAL).

The seasonal evolution revealed in Table I and Figure 2 is described in detail by Saïd et al. (2009). The principal 
Table I. Details of the flights. The horizontal line separates the early from the active monsoon phase. Time UTC in the third column is the median time over the considered duration of the flight.

\begin{tabular}{|c|c|c|c|c|c|c|c|c|c|c|c|c|c|c|c|}
\hline FL & $\begin{array}{l}\text { Date/time } \\
\mathrm{mm} / \mathrm{dd} \text { UTC }\end{array}$ & $\overline{Z_{\mathrm{i}}}$ & Legs & $\bar{U}$ & $\overline{\theta_{\mathrm{v}}}$ & $\overline{r_{\mathrm{v}}}$ & $w_{*}$ & $\Delta U$ & $\Delta \theta_{\mathrm{v}}$ & $\Delta r_{\mathrm{v}}$ & $\gamma$ & $\delta Z_{\mathrm{i}} / \delta t$ & $w_{\mathrm{e}}$ & $\beta$ & ITD \\
\hline 17 & 06/05 1435 & 1596 & $0.1-0.7 Z_{\mathrm{i}}$ & 6.9 & 311.7 & 15.7 & 2.4 & 6.3 & 1.4 & -6.5 & 2.4 & 11.7 & 2.9 & 0.30 & 18.8 \\
\hline 18 & $06 / 061336$ & 1535 & $9 Z_{\mathrm{i}}$ & 3.2 & 312.1 & 0.6 & & 9.1 & 0.8 & 4.0 & & 13.8 & -0.6 & -0.03 & 20.4 \\
\hline 21 & $06 / 111326$ & 1482 & $3 / 0.1-0.5 Z_{\mathrm{i}}$ & 4.0 & 309.6 & 15.0 & 1.5 & 7.9 & 2.0 & -6.7 & 2.2 & 4.2 & 0.6 & 0.18 & 20.4 \\
\hline 22 & $06 / 121406$ & 1446 & $6 / 0.1-0.6 Z_{\mathrm{i}}$ & 0.5 & 309.3 & 15.3 & 1.9 & 6.2 & 2.0 & -6.8 & 2. & 3.6 & 1.0 & 16 & 19.0 \\
\hline 26 & $06 / 151245$ & 1153 & $6 / 0.2-0.8 Z_{\mathrm{i}}$ & 8.5 & 307.8 & 12.8 & 2.0 & 15.9 & 2.2 & -4.6 & 1.4 & 5.5 & 3.1 & 0.32 & 16.9 \\
\hline 34 & 07/10 1347 & 1409 & $3 / 0.1$ & 3.2 & 310.0 & 15.2 & 1.7 & 10.2 & 3.0 & -6.8 & 1.6 & 0.0 & 2.5 & 0.48 & 19.6 \\
\hline 35 & $07 / 12 \quad 1503$ & 1720 & $4 / 0.1-0.8 Z_{\mathrm{i}}$ & 7.4 & 311.0 & 14.6 & 1.5 & 5.9 & 1.5 & -7.0 & 1.8 & 5.3 & 0.7 & 0.10 & 19.5 \\
\hline 36 & $07 / 131346$ & 1935 & $4 / 0.2-0.9 Z_{\mathrm{i}}$ & 6.4 & 310.5 & 15.0 & 2.1 & 9.7 & 2.0 & -6.6 & 2.0 & 12.5 & 1.6 & 0.23 & 17.8 \\
\hline 41 & $08 / 051424$ & 800 & $3 / 0.1-0.8 Z_{\mathrm{i}}$ & 4.3 & 306.0 & 18.2 & 1.3 & 3.4 & 1.8 & -3.2 & 3.3 & 7.4 & 0.7 & 0.14 & 21.3 \\
\hline 42 & 08/06 1706 & 869 & $4 / 0.3-0.8 Z_{\mathrm{i}}$ & 3.6 & 304.9 & 16.4 & 0.1 & 3.0 & 2.5 & -6.9 & 3.8 & 0.0 & 0.1 & 0.23 & 22.3 \\
\hline 43 & 08/07 1315 & 838 & $3 / 0.2-0.9 Z_{\mathrm{i}}$ & 3.3 & 305.5 & 17.4 & 1.2 & 7.7 & 3.3 & -4.4 & 5.0 & 4.2 & 0.1 & 0.02 & 21.3 \\
\hline 50 & 08/12 1640 & 900 & $2 / 0.2-0.7 Z_{\mathrm{i}}$ & 2.0 & 306.5 & 16.6 & 0.8 & 3.8 & 3.0 & -6.6 & 3. & 0.0 & -0.2 & -0.37 & 21.4 \\
\hline 51 & $08 / 131403$ & 1116 & $4 / 0.1-0.9 Z_{\mathrm{i}}$ & 3.2 & 307.7 & 16.6 & 1.3 & 6.6 & 1.0 & -4.6 & 2.9 & 12.5 & 0.9 & 0.14 & 21.9 \\
\hline 56 & 08/17 1018 & 632 & $4 / 0.2-0.8 Z_{\mathrm{i}}$ & 5.4 & 304.1 & 18.5 & 0.9 & 3.1 & 1.7 & -1.8 & 4.4 & 6.9 & 1.1 & 0.25 & 18.8 \\
\hline 58 & 08/19 1413 & 1031 & $3 / 0.1-0.7 Z_{\mathrm{i}}$ & 4.9 & 306.4 & 16.0 & 1.4 & 7.8 & 2.7 & -6.5 & 2.5 & 8.3 & 0.7 & 0.25 & 20.7 \\
\hline
\end{tabular}

FL: flight number. $\overline{Z_{\mathrm{i}}}$ : PBL mean depth $(\mathrm{m})$.

Legs: the number of flight legs in the PBL, followed by the minimum and maximum height of the legs.

$\bar{U}, \overline{\theta_{\mathrm{v}}}, \overline{r_{\mathrm{v}}}$ : mean wind $\left(\mathrm{m} \mathrm{s}^{-1}\right)$, virtual potential temperature $(\mathrm{K})$ and water vapour mixing ratio $\left(\mathrm{g} \mathrm{kg}^{-1}\right)$ in the PBL during the sounding. $\Delta$ denotes the jump in these variables between the SAL and PBL.

$\gamma$ : virtual potential temperature lapse rate $\left(10^{-3} \mathrm{~K} \mathrm{~m}^{-1}\right)$ in the lower part of the SAL.

$w_{*}$ : convective velocity scale $\left(\mathrm{m} \mathrm{s}^{-1}\right) . w_{\mathrm{e}}$ : entrainment velocity $\left(\mathrm{cm} \mathrm{s}^{-1}\right) . \delta Z_{\mathrm{i}} / \delta t$ : PBL growth rate $\left(\mathrm{cm} \mathrm{s}^{-1}\right)$.

$\beta$ : ratio of entrainment buoyancy flux to surface buoyancy flux.

ITD: Latitude $\left({ }^{\circ} \mathrm{N}\right)$ of the Intertropical discontinuity at Niamey longitude at 1200 UTC.

changes identified between the early monsoon phase and active monsoon phase are a decrease in temperature, increase in humidity, and a decrease in PBL depth and convective turbulence due to the moistening of the ground by the rains that occur in the active monsoon phase. The lapse rate above the PBL is often small - even close to neutral - during the first period, favouring rapid growth of the PBL. Based on the differences from one period to the other, we expect entrainment to play a different role.

$\Delta r_{\mathrm{v}}$ is large during the pre- or early monsoon period, about $6 \mathrm{~g} \mathrm{~kg}^{-1}$. At this stage, moisture is starting to penetrate the area through incursions of the monsoon flow into the SAL, but the latter is still very dry. During the active monsoon phase, the entire troposphere is much more humid and $\Delta r_{\mathrm{v}}$ is usually smaller. The three cases in which $\Delta r_{\mathrm{v}}$ is still large $\left(>6 \mathrm{~g} \mathrm{~kg}^{-1}\right)$ during the second period were flights made the day after deep convective rainfall. The large $\Delta r_{\mathrm{v}}$ observed then are due to the drying of the mid-troposphere which usually follows the passage of a deep convective system.

\section{Small-scale subsident dry tongues and impact on the PBL structure}

\subsection{Observation of dry tongues}

Figure 3 shows examples of fluctuations $w^{\prime}, \theta^{\prime}$, and $r_{\mathrm{v}}^{\prime}$ that were measured right below the PBL top in the first period
(6 June 2006). It shows some marked concomitances of negative fluctuations in water vapour content and in air vertical velocity associated with positive fluctuations in potential temperature. This is the manifestation of intrusions of dry air from the SAL into the PBL, of a few hundred metres wide and a few $\mathrm{km}$ apart. We hereafter call them 'dry tongues', as previously used by Couvreux et al. (2007) in their study of the dry convective PBL during the International $\mathrm{H}_{2} \mathrm{O}$ Project (IHOP; Weckwerth et al., 2004).

The impact of similar dry tongues on PBL growth was previously studied during IHOP (Couvreux et al., 2005, 2007) with a large-eddy simulation (LES). They were also observed during HAPEX Sahel (Hydrological and Atmospheric Pilot Experiment) in the same area by Lothon et al. (2007). Those works showed that the dry tongues are responsible for negative skewness of $r_{\mathrm{v}}$ distribution at least in the upper part of the PBL and play a crucial role in the diurnal drying and growth of the PBL. For the example shown in Figure 3, the PBL growth rate was $14 \mathrm{~cm} \mathrm{~s}^{-1}$. This is a general observation during the AMMA campaign: at the time of the ATR flights $(\sim 1100$ to 1500 UTC), the PBL often grew rapidly, as shown by Saïd et al. (2009). (Note that in this region there is a one-hour delay between universal and local times.)

In order to characterize the scales associated with the dry tongues, we arbitrarily define the dry tongues with the following procedure: we look for fluctuations for which $w^{\prime}<0, \theta^{\prime}>0$ and $r_{\mathrm{v}}^{\prime}<0.05 \Delta r_{\mathrm{v}}$. Those selected 

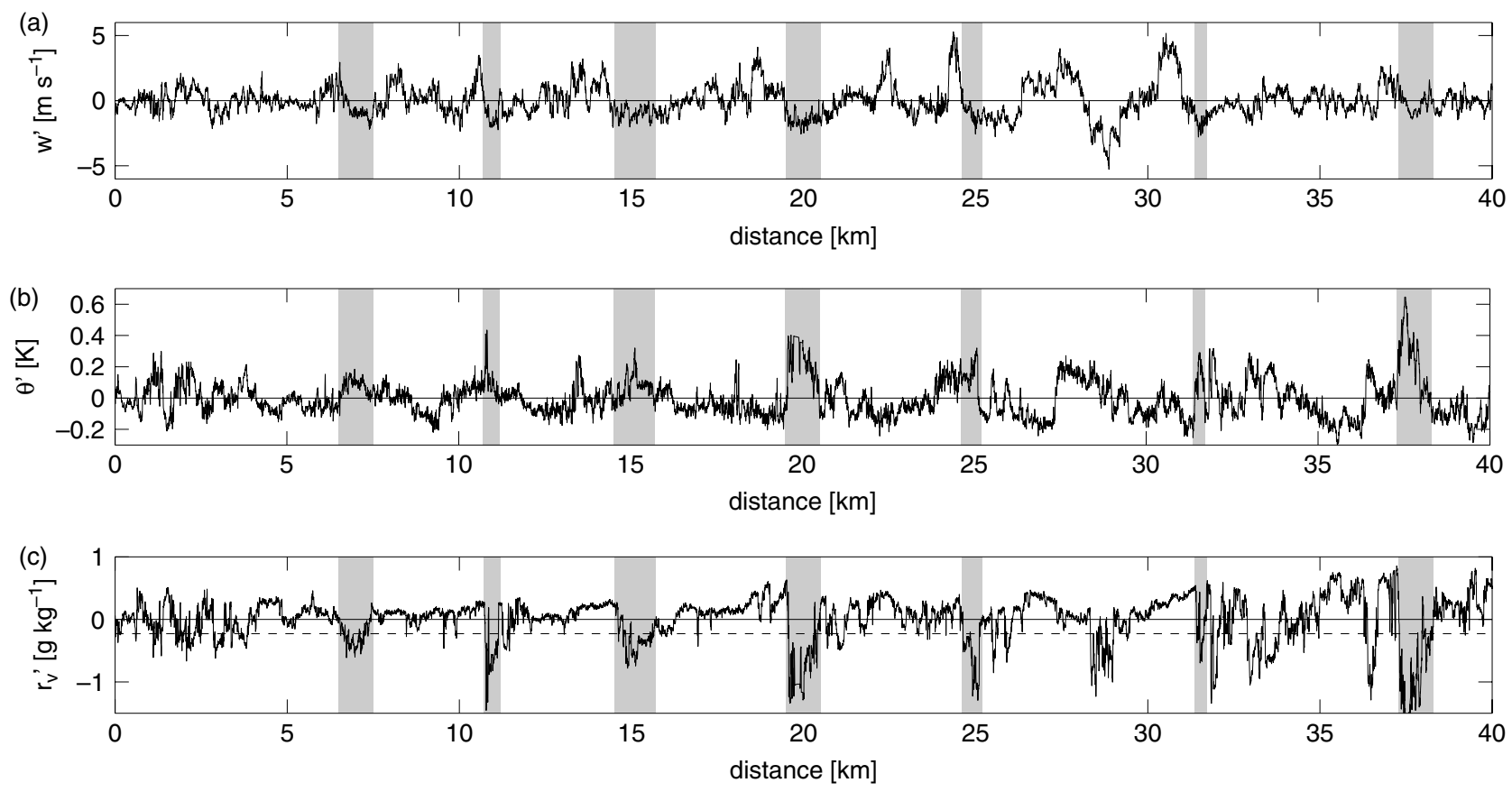

Figure 3. $25 \mathrm{~Hz}$ time series of the fluctuations in (a) $w^{\prime}$, (b) $\theta^{\prime}$ and (c) $r_{\mathrm{v}}^{\prime}$ during part of one leg flown at $0.97 Z_{\mathrm{i}}$ on 6 June 2006 . Shaded areas indicate dry tongues as defined in section 3.1. In (c), the dashed line indicates the threshold $\left(0.05 \Delta r_{\mathrm{v}}\right)$ used in the selection of dry tongues.

fluctuations are used to define the dry tongues by considering all datapoints with $r_{\mathrm{v}}^{\prime}<0$ around the selected peak (that has $r_{\mathrm{v}}^{\prime}<0.05 \Delta r_{\mathrm{v}}$ ). Each dry tongue has a width $l$ obtained from the number of these datapoints (shaded areas in Figure 3(c)). The distance $D$ between dry tongues is defined as the distance between the centres of the dry tongues detected in this way. Defining the threshold of moisture-negative fluctations as the moisture jump across the inversion allows us to take into account the fact that the larger the inversion, the more intense the dry tongues.

The threshold of the moisture fluctuations can also be defined based on the standard deviation $\sigma_{r_{\mathrm{v}}}$. This is typically done to characterize thermals (Lenschow and Stephens, 1980) or, as in Nicholls (1989), for the study of entrainment in marine stratocumulus. $\sigma_{r_{\mathrm{v}}}$ is then different for each leg, while the criterium based on the jump across the inversion is the same for the stacked legs flown below it. The later method avoids selecting too many fluctuations that are not necessarily dry tongues directly coming from the SAL. It reduces the number of dry tongues in the lower part of the PBL during the active monsoon phase.

Note that the large negative threshold used here only selects strong events, i.e. those associated with the largest fluctuations in moisture.

On average, we find that $l=600 \pm 80 \mathrm{~m}$ and remains almost constant; only a slight increase occurs during the early monsoon phase, followed by a slight decrease. $l$ also remains constant with height (not shown). One could expect $l$ to decrease with decreasing height, however it increases slightly, which suggests that some air from the environment surrounding the dry intrusion is engulfed within and mixed with the dry air. Figure 4 shows $D$ as a function of normalized height $z_{*}=z / Z_{\mathrm{i}}$. It decreases from $2 \mathrm{~km}$ close to the top to $5 \mathrm{~km}$ close to the surface,

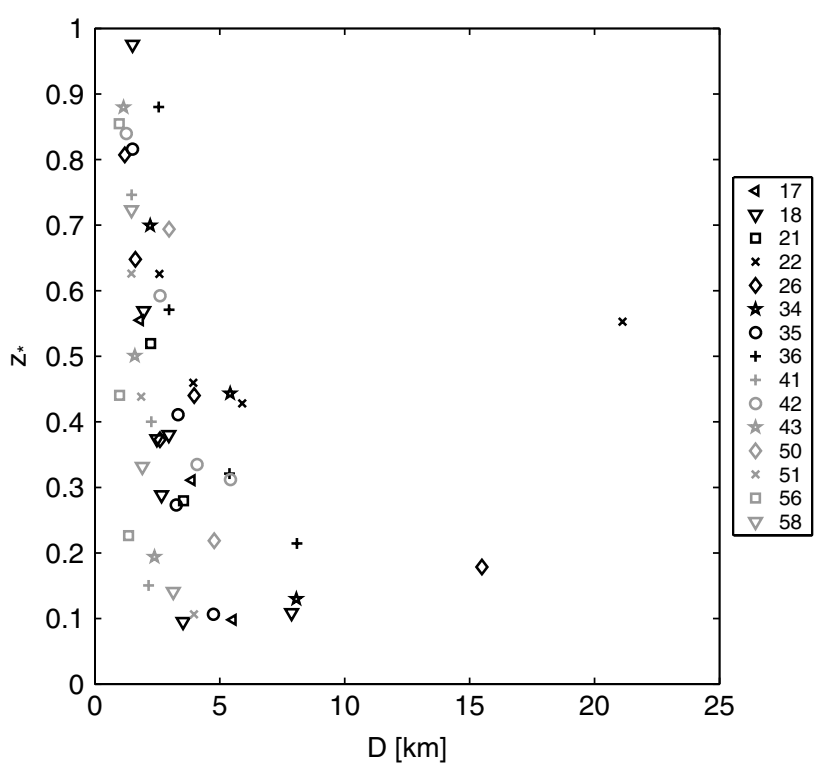

Figure 4. Vertical profile of distance $D$ between dry tongues as a function of normalized height for the 15 flights made during the early monsoon phase (black) and the active monsoon phase (grey).

which means that half of the dry tongues defined in that way travel down to the lower part of the PBL. This is consistent with the findings of Couvreux et al. (2007) using LES. In the mid-part of the PBL, $D=$ $4000 \pm 1800 \mathrm{~m}$ on average during the moistening period and is smaller $(2000 \mathrm{~m})$ during the wet period. We find exponential distributions of $D$ and $l$ (not shown) similar to those observed by Miao and Geerts (2006) for thermals in the convective boundary layer.

We can obtain the variation of the characteristics of the dry tongues with height by averaging all dry tongues 
found in the three thirds of the PBL depth: $0.66 \leq z_{*} \leq 1$, $0.33 \leq z_{*} \leq 0.66$ and $0 \leq z_{*} \leq 0.33$. This is done in Figure 5 for the early and active monsoon phases (left and right columns respectively). The width of each dry tongue is stretched so that they all fit into a non-dimensional width when averaged together. Figure 5 shows that the dry tongue becomes less dry and less warm as it penetrates down into the PBL, but gains kinetic energy, since $\left|w^{\prime}\right|$ increases from $Z_{\mathrm{i}}$ to the surface. This can be explained with decreasing positive buoyancy, favouring an increase of the descending motion. Couvreux et al. (2007) showed that the buoyancy can even become
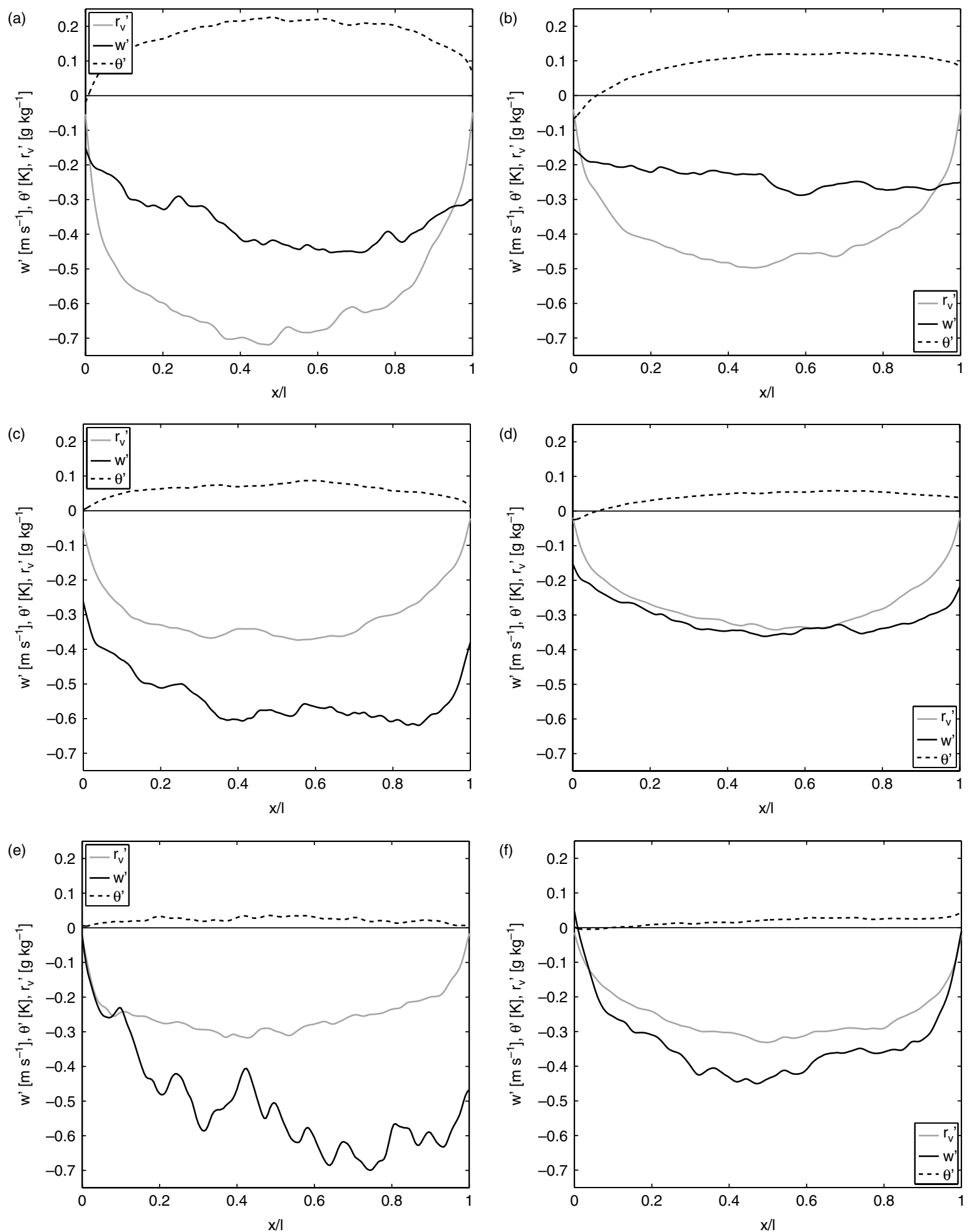

Figure 5. Composite dry tongues as a function of normalized height (upper third of PBL depth in (a,b) down to lower third in (e, f)), and as function of the period $\left((\mathrm{a}, \mathrm{c}, \mathrm{e})\right.$ is for the early monsoon phase, $(\mathrm{b}, \mathrm{d}, \mathrm{f})$ for the active monsoon phase). For each panel, fluctuations in $w^{\prime}$ (black), $\theta^{\prime}$ (dashed) and $r_{\mathrm{v}}^{\prime}$ (grey) are averaged over the set of dry tongues found in a given layer and period. The $x$-axis is a dimensionless distance relative to the total width of the dry intrusion. 
negative, which substantially increases the descending motion toward the lower part of the PBL. Note that the authors select their dry tongues with a criterion based only on the water vapour fluctuation, which allows $\theta^{\prime}$ to be sometimes negative within the dry tongue.

During the active monsoon phase, this vertical structure is observed with a smaller magnitude of fluctuations associated with the dry tongues. In both periods, the change from the top to the middle part of the PBL is more significant than from the middle to the lower part.

\subsection{PBL vertical structure}

The stacked legs flown by the ATR allowed us to obtain vertical profiles of the turbulence structure. For all flights, those legs were flown between 1200 and 1430 UTC.

The subsident dry tongues described above are associated with large water vapour variance in the upper part of the PBL and negative skewness of the water vapour fluctuations distribution throughout the entire depth (Figure 6(a)), as previously found by Couvreux et al. (2007) in the Great Plains. The skewness $S_{r_{\mathrm{v}}}$ of the water vapour distribution is defined by

$$
S_{r_{\mathrm{v}}}=\frac{\overline{r_{\mathrm{v}}^{\prime 3}}}{\left(\overline{r_{\mathrm{v}}^{\prime 2}}\right)^{3 / 2}} .
$$

Negative $S_{r_{\mathrm{v}}}$ reflects the occurrence of more negative than positive fluctuations. It is linked here to the large jump in humidity at the top of the PBL and intrusions of dry air from the SAL (Couvreux et al., 2007) which skew the distribution. The vertical profiles of $S_{r_{\mathrm{v}}}$ display a minimum around $0.4 Z_{\mathrm{i}}$ (Figure $6(\mathrm{~b})$ ), with values as low as -1 or less. This means that the impact of the dry tongues can be detected at very low levels. Lohou et al. (2009) show how dry tongues may actually reach the surface. During the active monsoon phase, $S_{r_{\mathrm{v}}}$ is less negative and can become positive close to surface due to moister ground and significant latent heat flux in the surface layer (Saïd et al., 2009). It can also be positive at the top, likely due to clouds. During the early monsoon phase $S_{r_{\mathrm{v}}}$ is more negative, on average, than during the active monsoon phase. A Student test on the statistics reveals that the observed difference is significant.

Vertical profiles of normalized heat and moisture vertical fluxes for the 15 flights are shown in Figure 7. Heat fluxes are normalized with surface fluxes obtained by linearly extrapolating the observed profiles. For moisture fluxes, we use a different normalisation according to the period, because of close-to-zero fluxes at the surface before the first rain. For the early monsoon phase (first eight flights), moisture fluxes are normalized by the moisture flux extrapolated at $Z_{\mathrm{i}}$. Heat and moisture flux profiles are only slightly scattered during this period, denoting the consistent processes that occur in the early part of the monsoon setting. Heat flux decreases with height and reaches negative values at $Z_{i}$, whereas moisture flux increases from close to zero at the surface to large fluxes at the PBL top. The source of turbulence for water vapour scalar is mainly at the PBL top, associated with the dry tongues which contrast with the moister penetrating updraughts. Only one flight out of eight in the first period does not show increasing moisture flux with height (FL 36), so we normalized it via the surface latent heat flux. FL 35 and FL 36 are in fact the only flights in this first period for which it rained earlier (on 11 July, the day before FL 35 and two days before FL 36). Those profiles are typical of dry PBL (Couvreux et al., 2005).

For the active monsoon phase, moisture flux can be normalized by the surface flux because of moister ground. The slope of the flux divergence can be either positive or negative, according to the amount of entrainment relative to the surface flux. The increase in the surface latent flux from the pre-onset to the post-onset is accompanied by a decrease in surface sensible heat flux from 100 $200 \mathrm{~W} \mathrm{~m}^{-2}$ to $<100 \mathrm{~W} \mathrm{~m}^{-2}$. The surface latent heat flux increases from zero to $200-400 \mathrm{~W} \mathrm{~m}^{-2}$ (Saïd et al., 2009).
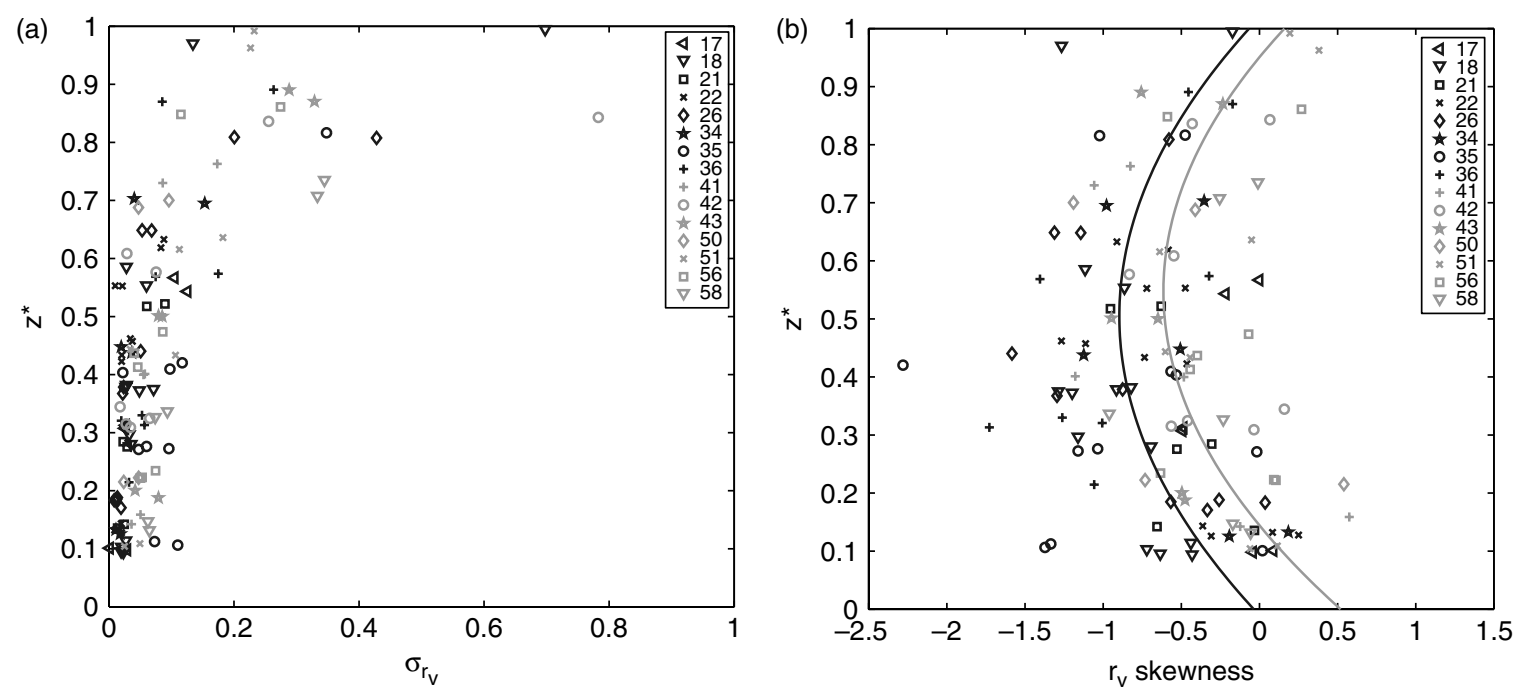

Figure 6. Vertical profiles of (a) $r_{\mathrm{v}}$ standard deviation and (b) $r_{\mathrm{v}}$ skewness, with black (grey) symbols denoting the early (active) monsoon phase. Solid lines in (b) represent 2 nd-degree polynomial least-square fits for the two monsoon phases. 

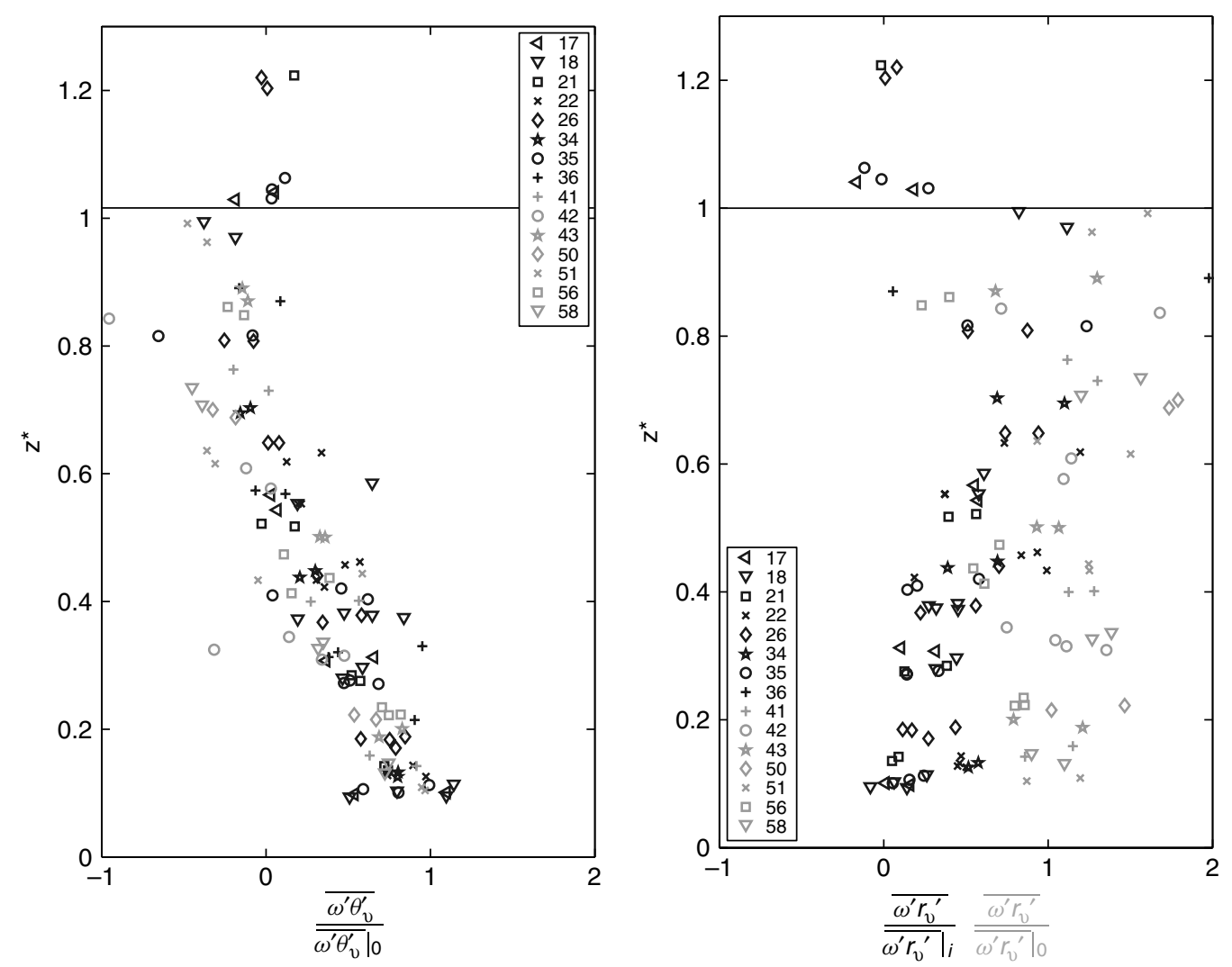

Figure 7. Profiles of normalized (a) heat flux and (b) moisture flux. Black and grey symbols are as in Figure 6.

3.3. Contribution of dry tongues to the variances and fluxes

In order to estimate the contribution of dry tongues to the variances and fluxes relative to the contribution of thermals, we make a conditional analysis of the fluctuations $w^{\prime}, \theta^{\prime}$ and $r_{\mathrm{v}}^{\prime}$ (Grossman and Nimal, 1995). We define three classes: thermals with $w^{\prime}>0$ and $\theta^{\prime}>0$, dry tongues with $w^{\prime}<0, r_{\mathrm{v}}^{\prime}<0$ and $\theta^{\prime}>0$ with the remaining population in the third class.

Here the definition of dry tongues is simplified relative to the criteria used previously to estimate the associated length-scales, so that there is no arbitrary threshold used. This will provide an estimate of the extent to which the descending positively buoyant air parcels contribute to fluxes, rather than the most marked dry tongues previously described in detail.

Figure 8 shows the result of the conditional analysis within three layers in the PBL (the same as in Figure 5). Figures 8(a) and (b) represent the distribution of datapoints over the three classes. Figures 8(c) and (d) show the contribution of each class to water vapour variance $\sigma_{r_{\mathrm{V}}}^{2}$ and Figures 8(e) and (f) show the contribution of each class to potential temperature variance $\sigma_{\theta}^{2}$. Since neither thermals nor dry tongues occupy large areas, they are both less statistically probable (Figure 8(a) and (b)). However, their contribution to variances and fluxes (the latter is not shown) is predominant. The contribution of thermals to $\sigma_{\theta}^{2}$ is predominant near the surface, as in a typical convective PBL (58\% and $48 \%$ respectively for the two phases) and decreases with $z_{*}$ to approximately
$20 \%$ close to $Z_{\mathrm{i}}$. On the contrary, the contribution of the dry tongues becomes predominant to $\sigma_{r_{\mathrm{v}}}^{2}$ from $z_{*}=0.3$ up to the PBL top. The maximal contribution of the dry tongues to $\sigma_{r_{\mathrm{v}}}^{2}$ in the middle PBL is likely connected to the maximal skewness at the same height (Figure 6(b)). Near the PBL top, $\sigma_{r_{\mathrm{v}}}^{2}$ is at its maximum and mainly due to the dry tongues. In the middle part, where the variance of $r_{\mathrm{v}}$ is much smaller, their relative contribution to $\sigma_{r_{\mathrm{V}}}^{2}$ is slightly larger than above. However the dry tongues are not the most represented class. The difference, although small, between the middle and upper layers could be due to an increased intake of boundarylayer air $\left(w^{\prime}<0, \theta^{\prime}<0, r_{\mathrm{v}}^{\prime}>0\right)$ by the dry tongues in the entrainment layer. Considering $\theta_{\mathrm{v}}$ rather than $\theta$ generally results in a larger contribution of thermals in the middle PBL relative to the previous analysis, but the contribution of dry descents remains predominant in the upper part.

\section{Entrainment}

Dry tongues are entirely part of the entrainment process at the PBL top. It is important to estimate how large the entrainment is in this context and how its contribution and role evolve during the monsoon setting. Its possible role in slowing down the monsoon through inhibition of convection by drying the lower troposphere, or in favouring it by transporting humidity from the low troposphere to the mid-troposphere after it has been 

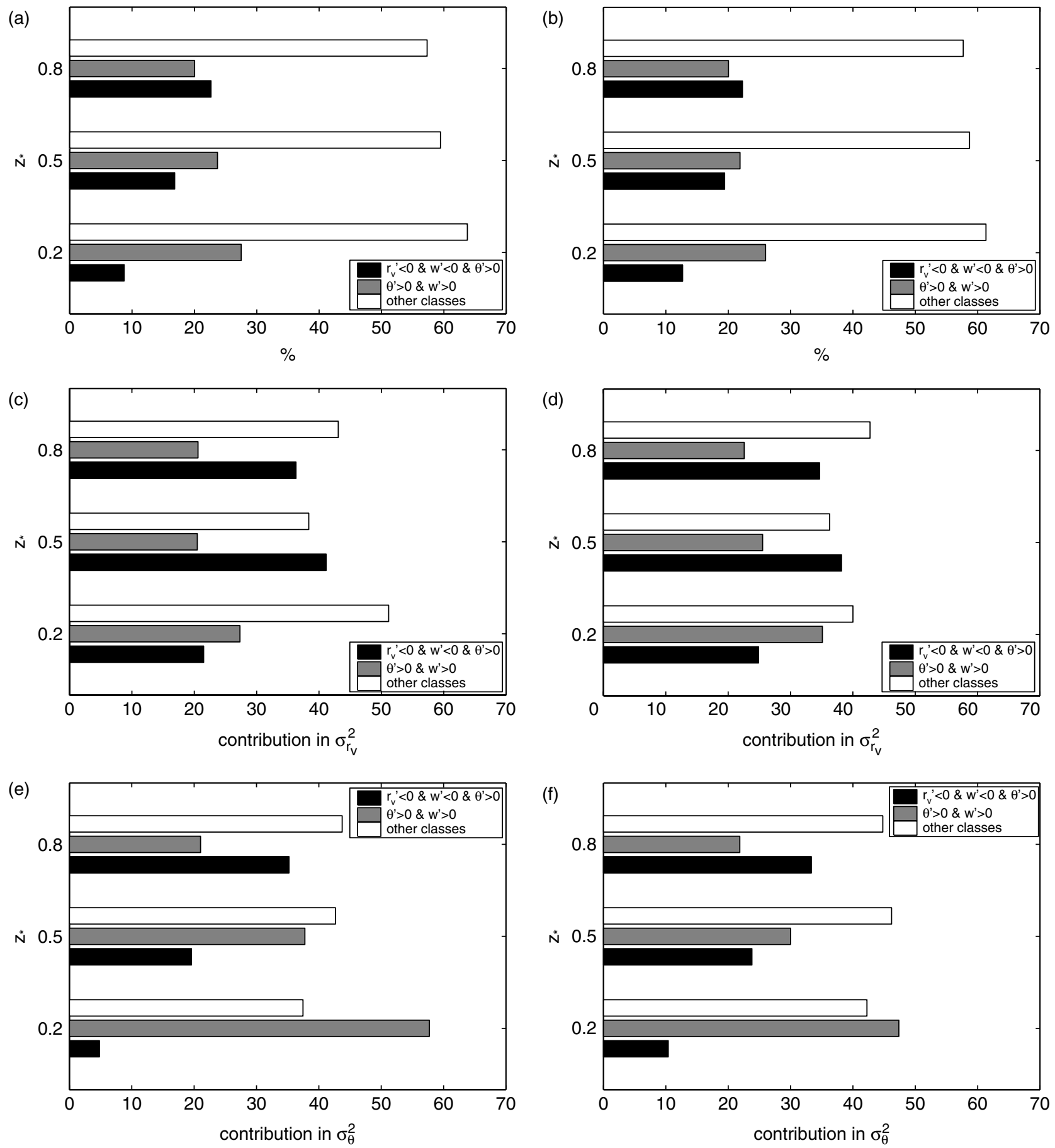

Figure 8. (a, b) Distribution of data points over different classes, (a) during the early monsoon phase and (b) during the active monsoon phase. Contribution of the same classes to $(c, d)$ humidity variance and $(e, f)$ potential temperature variance.

advected by the nocturnal jet, makes the issue important to address.

A usual estimate of entrainment at the PBL top is obtained by the ratio $\beta$ of entrainment buoyancy flux to surface buoyancy flux:

$$
\beta=-\frac{\left.\overline{w \theta_{\mathrm{v}}}\right|_{i}}{\left.\overline{w \theta_{\mathrm{v}}}\right|_{0}} .
$$

Both fluxes are extrapolated from the profiles shown in Figure 7. Estimates of $\beta$ for each flight are shown in Table I.
The entrainment velocity is defined by

$$
w_{\mathrm{e}}=\frac{\partial Z_{\mathrm{i}}}{\partial t}-w_{\mathrm{h}},
$$

where $w_{\mathrm{h}}$ is the large-scale vertical velocity. $w_{\mathrm{h}}$ is usually small or of the same magnitude as $w_{\mathrm{e}} . w_{\mathrm{e}}$ quantifies the engulfment of air from the free troposphere within the PBL. It can be estimated through the buoyancy flux at the PBL top and the jump of virtual potential temperature 


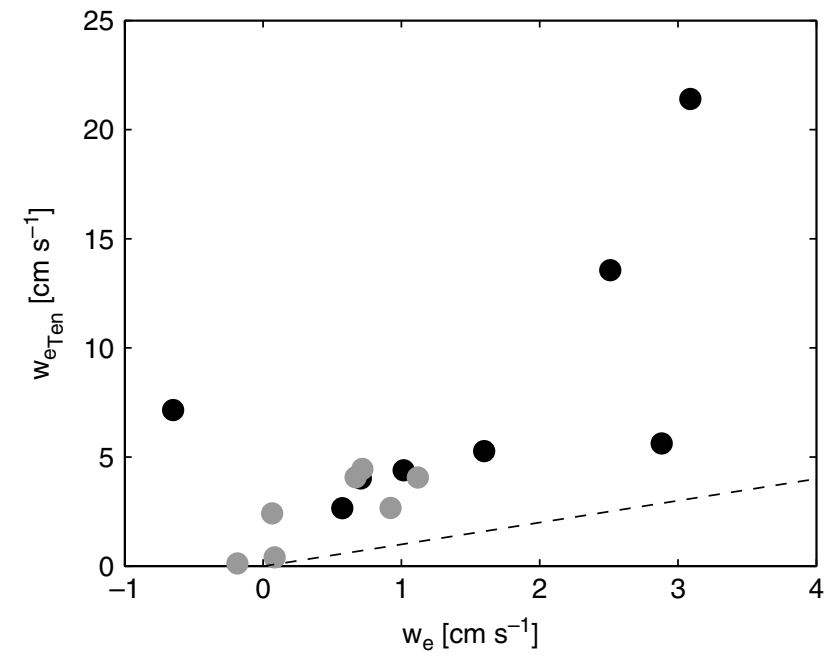

Figure 9. Entrainment velocity as given by the mixed-layer model of Tennekes (1973) versus the observed $w_{\mathrm{e}}$. Black and grey symbols are as in Figure 6.

(Lenschow et al., 1999):

$$
w_{\mathrm{e}}=-\frac{\left.\overline{w \theta_{\mathrm{v}}}\right|_{i}}{\Delta \theta_{\mathrm{v}}} .
$$

Uncertainty on $w_{\mathrm{e}}$ arises from several uncertainties on estimates of fluxes (random error only, since systematic error has been taken into account), on $Z_{\mathrm{i}}$ (since $\left.\overline{w \theta_{\mathrm{v}}}\right|_{\mathrm{i}}$ is extrapolated at $Z_{\mathrm{i}}$ ) and on $\Delta \theta_{\mathrm{v}}$. If an error of $\pm 0.5 \mathrm{~K}$ is assumed for the jump in potential temperature, and 100 or $200 \mathrm{~m}$ for $Z_{\mathrm{i}}$, we find that the flux random error has the largest contribution to the error on $w_{\mathrm{e}}$; it is always larger than $20 \%$.

For eight out of 15 flights, we observe that $\beta$ is larger than the typical 0.2 (Table I) used in many parametrisations (Garratt, 1992). The average is 0.22 during the early monsoon phase and 0.10 during the active monsoon phase. Therefore, entrainment is significantly smaller during the second period. Similarly the mean $w_{\mathrm{e}}$ is about $1.5 \mathrm{~cm} \mathrm{~s}^{-1}$ during the first period whereas it is $0.5 \mathrm{~cm} \mathrm{~s}^{-1}$ during the second.

Flight 18 (6 June) is an unusual case of early monsoon phase, large surface heating, and a clear sky, but negligible entrainment, according to our estimates. It represents a situation in which the ITD had a very large retreat to the south and even most likely crossed the area during the flight, as the wind turned very slightly eastward. It reveals widespread unstable conditions and sheds uncertainty on any estimate that assumes relative homogeneity. Meanwhile, however, it represents a very interesting case.

In Figure 9, we compare our estimates of entrainment velocity with that predicted by the simple mixed-layer theory of Tennekes (1973), who assumes a zero largescale velocity $w_{\mathrm{h}}$ and negligible advection:

$$
w_{\mathrm{e} \text { Ten }}=(1+2 \beta) \frac{\left.\overline{w \theta}\right|_{0}}{\gamma Z_{\mathrm{i}}} .
$$

In this equation, $\left(\left.\overline{w \theta}\right|_{0}\right) /\left(\gamma Z_{\mathrm{i}}\right)$ quantifies the encroachment and

$$
\frac{2 \beta}{(1+2 \beta)} \frac{\left.\overline{w \theta}\right|_{0}}{\gamma Z_{\mathrm{i}}}
$$

quantifies the contribution of entrainment (Garratt, 1992). Considering Equation (6) and our estimates of $\beta$, we find a contribution of entrainment to the total growth rate (which is equal to $2 \beta /\{1+2 \beta\}$ ) of $30 \%$ on average in the first period and about $15 \%$ in the second. The remaining contribution is due to encroachment.

With the assumption that $w_{\mathrm{h}}$ is small relative to other velocities in Equation (4), our estimates of $w_{\mathrm{e}}$ from (5) should be of the same magnitude as the PBL growth $\partial Z_{\mathrm{i}} / \partial t$ (Table I) and as $w_{\mathrm{e}}$. . Our estimates are approximately 5 and up to 10 times smaller.

There are several possible explanations for these discrepancies: it is very difficult to estimate $\Delta \theta_{\mathrm{v}}$ from soundings, because they often reveal a complex vertical structure, and above all, as we said before, this structure can vary with time and space. It is especially difficult to calculate the jumps accurately during the second period when clouds are present.

A positive $w_{\mathrm{h}}$ would explain smaller entrainment velocity than observed PBL growth, but this is rare. However, the context of the ITD convergence of dry static energy could be associated with large-scale convergence overcapped by the ITCZ subsidence branch. This is consistent with the scheme found by Peyrille and Lafore (2007) with a 2D model (Figure 1). We found $\left|w_{\mathrm{h}}\right|<2 \mathrm{~cm} \mathrm{~s}^{-1}$ using National Centers for Environmental Prediction (NCEP) and European Centre for Mediumrange Weather Forecasts (ECMWF) analyses and also using the divergence of the horizontal wind measured by use of a network of wind profilers (Lee et al., 2007). The ECMWF and NCEP analyses showed a large variability of $w_{\mathrm{h}}$ in space and time that did not allow us to retrieve a reliable estimate. Lee et al. (2007) analyzed the synoptic circulation during the month of July 2006 and found subsident air on average in the lower free troposphere, with successive episodes of both divergence and convergence of magnitudes that could generally not explain the discrepancy in Figure 9.

The most likely explanation for the discrepancy observed in Figure 9 lies in the hypothetis of a first-order jump in Equation (5), that is an infinitely thin inversion depth associated with a sudden jump in $\theta_{\mathrm{v}}$.

Equation (6) does not take into account the contribution of shear at the surface or at the top of the PBL, which are known to play a key role in $\beta$ and $w_{\mathrm{e}}$ (Fedorovich and Conzemius, 2008), but they would not explain such a difference. Neither errors on the jumps nor on the large-scale vertical velocity can explain such a difference between $\partial Z_{\mathrm{i}} / \partial t$ and $w_{\mathrm{e}}$ or between $w_{\mathrm{e}}$ and $w_{\mathrm{e}}$. A rapid variation of the flux profiles - although linearly varying with height - and of the structure of the entrainment zone (depth and scalar jumps) is more likely responsible.

During the first period, $\beta$ takes a large spectrum of values from close to 0 to 0.48 at maximum, so that it is neither constant nor equal to the typical value of 0.2 used 


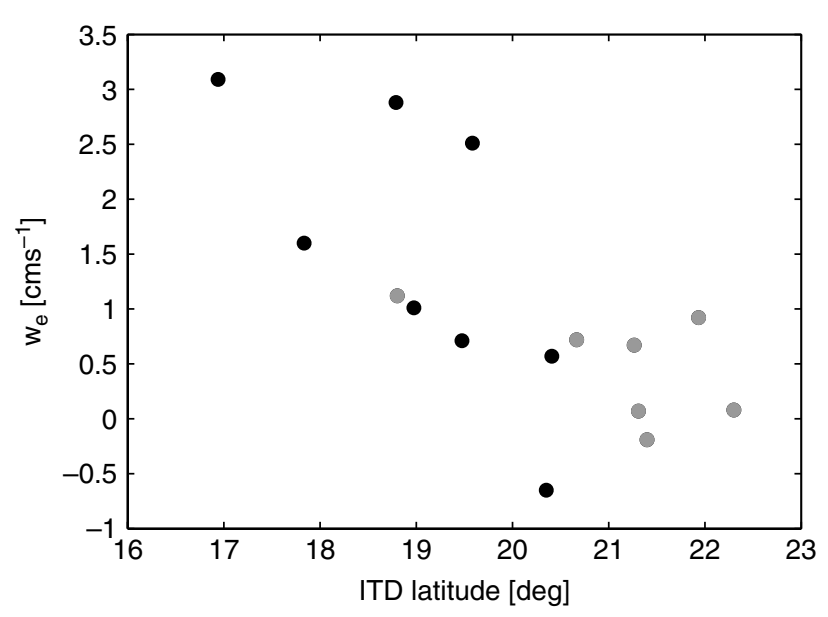

Figure 10. Entrainment velocity as a function of the ITD latitude at Niamey longitude. Black and grey symbols are as in Figure 6.

in many models for the parametrisation of entrainment and closure at the PBL top. According to several authors cited by Fedorovich and Conzemius (2008), this suggests that the contribution of shear at the surface and at the PBL top can vary from case to case. This result was also recently observed by Lothon et al. (2009) in convective PBL over Illinois, USA, based on estimates of vertical profiles of normalized turbulent kinetic energy (TKE) dissipation rates using the spectra of the vertical velocity measured by Doppler lidar.

Our estimates of entrainment did not agree either with simple models (e.g. Mahrt and Lenschow, 1976) or with the recent parametrisations (e.g. Pino, 2006) of the contribution of shear at surface and shear at the PBL top based on the integration of the TKE budget over the PBL depth. Meanwhile, our observations based on aircraft-measured momentum fluxes and wind profiles show that the shear can be significant in the whole PBL (Saïd et al., 2009) so that it does not generate TKE only within close proximity of the interfaces. Another unexpected result is that the wind shear at the PBL top, which is difficult to estimate for the same reasons as $\Delta \theta_{\mathrm{v}}$, is not well correlated to $\Delta \theta_{\mathrm{v}}$. So we need further work on the TKE budget using both the aircraft observations and LES sensitivity studies, to address this issue.

In spite of the limits encountered in explaining our estimates of entrainment at the interface between the monsoon and the harmattan, we find a very good correlation between the latitudinal position of the ITD at 1200 UTC and our estimates of entrainment through $\beta$ (not shown) or $w_{\mathrm{e}}$ (Figure 10).

Here we use the ITD latitude position at the longitude of Niamey estimated from the ECMWF analyses at $0.25^{\circ}$ horizontal resolution by Lothon et al. (2008). It is mainly based on the detection of the local maximum of $2 \mathrm{~m}$ dew point temperature meridional gradient. Because of turbulent mixing during the day, the position of the ITD at midday has a significant uncertainty, but it shows a consistent variability on the seasonal and diurnal scale (Lothon et al., 2008); the correlation that we observe here is significant. The correlation is predominantly due to the correlation of the buoyancy flux at the PBL top and the ITD position. It is larger with the ITD absolute position (correlation coefficent of 0.6) than with the relative distance between the flight exploration area and the ITD (0.4). However, our substantial uncertainty on both variables leads us to be cautious in interpreting these values. Since the ITD is located further north during the wet period and entrainment is smaller at that point due to the cloudier, moister and colder PBL, part of the correlation is built in this way. But the correlation is also very good when considering only the flights made during the first period, when the ITD is still largely oscillating back and forth before setting in further north at a more stable latitude. The oscillations of the ITD at the intraseasonal scale during the pre-onset phase can be associated with the surges and retreats of the monsoon as discussed by Couvreux et al. (2009), and that they explain with the variability of the intensity of the Saharan heat low. During the active monsoon, other processes come into the picture of the ITD intraseasonal variablity. For example, Cuesta et al. (2009) discuss the influence of the AEWs which are generated in the flank of the AEJ, and Flamant et al. (2009) show that the cold pools issued from mesoscale convective systems developing over the Sahel can push the ITD northward as they propagate. All those large-scale processes impose their scale on the PBL through the associated surface flux and radiative forcings. Figure 10 reveals that a coupling is significant between the small-scale exchanges that occur at the monsoon/SAL interface and the large-scale context, with more entrainment observed for a southern position of the ITD. It also suggests that the same PBL processes are involved during the intraseasonal variability of the ITD and over a diurnal cycle, even if the causeeffect relationship cannot be of the same nature. This is consistent with the results of Kalapureddy et al. (2009) on African Easterly Jet/PBL interaction. Indeed, Miller et al. (2001) showed with a one-dimensional shallow-water model the crucial role of surface friction and inversion erosion in the diurnal oscillation of a dry line, whose properties are very similar to the ITD. The analysis made by Parker et al. (2005) and later by Lothon et al. (2008), both based on observations made in West Africa, gave further support to the role of the PBL processes in the diurnal oscillation of the ITD. Those processes remain involved at the intraseasonal scale, in spite of the different framework of the large-scale forcing processes.

\section{Concluding remarks}

The Sahelian PBL develops during the summer within the monsoon flow with overlying SAL. This gives specific characteristics to the entrainment at the top of the PBL, with a large contribution from dry tongues penetrating from the SAL down into the monsoon PBL. We made estimates of entrainment associated with them, characterized their scales and showed their impact on the vertical structure of the PBL. 
We have shown that it remains difficult to estimate entrainment, although the numerous legs within the PBL and SAL enabled us to describe the vertical structure of the PBL with satisfactory statistics, never achieved before. Up to now, only aircraft measurements have allowed us to measure the vertical structure of heat fluxes, and can provide estimates of entrainment rate and velocity. However, the combination of those observations with those of a Doppler lidar, which can measure with high spatial and temporal resolution the vertical structure of the entrainment zone, would be very fruitful. It can be used either by scanning the PBL with RHI (Traeumner et al., 2009), pointing up from the ground toward zenith with the hypothesis of frozen turbulence (Lothon et al., 2009) or downward from an aircraft (Flamant et al., 1997). The accurate study of the entrainment zone can provide direct estimates of entrainment ratio.

The dry tongues contribute significantly to variances and fluxes down to at least 0.6 to $0.4 Z_{\mathrm{i}}$. In fact Lohou et al. (2009) actually find an impact of entrainment processes down to the surface in a study based on measurements at the surface made during the same experiment.

We find larger entrainment during the first period, when the PBL top usually reaches the SAL and when surface heating is greater. The ratio of entrainment buoyancy flux over surface flux varies significantly between the different cases.

A preliminary study of the link between the smallscale exchanges at the ITD interface over the entire period of aircraft observations from early June to mid-August, when the ITD is always located north of the probed area of Niamey, showed that the larger the latitude of the ITD, the smaller the entrainment. This link is found even before the monsoon onset.

We still have to explain the large discrepancy between the observed entrainment velocity and the expected velocity from a rough theoretical estimate or from the observed PBL growth, because the uncertainty of the measured fluxes and scalar jumps cannot be the sole explanation. The best explanation lies in the zero-order jump assumption (Pino, 2006) in the definition used for the entrainment velocity estimates. A first-order jump should give better results.

We plan to further analyze the TKE budget along with the shear zone observed by the profilers in order to estimate the contribution of shear to entrainment. The coupling of our observations with LES of real and idea cases, with focused sensitivity studies, should improve our understanding of this issue.

Further, some differencies found between the two periods considered here are very likely due to the presence of clouds in the latter period. These need to be taken into account more explicitly in future analyses. When present, dry tongues often occur near the edge of the clouds, and microphysics processes such as evaporative cooling favour a decrease in buoyancy.

\section{Acknowledgements}

Based on a French initiative, AMMA was built by an international scientific group and is currently funded by a large number of agencies, especially from France, UK, USA and Africa. It has been the beneficiary of a major financial contribution from the European Community's Sixth Framework Research Programme. Detailed information on scientific coordination and funding is available on the AMMA International web site http://www.amma-international.org. The aircraft was operated by the Service des Avions Français Instrumentés pour la Recherche en Environnement (SAFIRE). We gratefully thank Yoonjung Lee and Fleur Couvreux for fruitful discussions.

\section{References}

Burpee RW. 1972. The origin and structure of easterly waves in the lower troposphere of North Africa. J. Atmos. Sci. 29: 77-90.

Cook K. 1999. Generation of the African Easterly Jet and its role in determining West African precipitation. J. Climate 12: 1165-1184.

Couvreux F, Guichard F, Redelsperger J-L, Kiemle C, Masson V, Lafore J-P, Flamant C. 2005. Water-vapour variability within a convective boundary layer assessed by large-eddy simulations and ihop-2002 observations. Q. J. R. Meteorol. Soc. 131: 2665-2693.

Couvreux F, Guichard F, Redelsperger J-L, Masson V. 2007. Negative water vapour skewness and dry tongues in the convective boundary layer: Observations and LES budget analysis. Boundary-Layer Meteorol. 123: 269-294.

Couvreux F, Guichard F, Bock O, Campistron B, Lafore J-P, Redelsperger J-L. 2009. Intraseasonal variability of the monsoon flux over West Africa prior to the monsoon onset. Q. J. R. Meteorol. Soc. 136(s1): 160-174

Cuesta J, Lavaysse C, Flamant C, Mimuni M, Knippertz P. 2009. Northward bursts of the West African monsoon leading to rainfall over the Hoggar massif, Algeria. Q. J. R. Meteorol. Soc. submitted.

Fedorovich E, Conzemius R. 2008. Effects of wind shear on the atmospheric convective boundary-layer structure and evolution. Acta Geophysica 56: 114-141.

Flamant C, Pelon J, Flamant P-H, Durand P. 1997. Lidar determination of the entrainment zone thickness at the top of the unstable marine atmospheric boundary layer. Boundary-Layer Meteorol. 83: $247-284$

Flamant C, Knippertz P, Parker DJ, Chaboureau J-P, Lavaysse C, Agusti-Panareda A, Kergoat L. 2009. The impact of a mesoscale convective system cold pool on the northward propagation of the intertropical discontinuity over West Africa. Q. J. R. Meteorol. Soc. 135: $139-159$.

Garratt JR. 1992. The atmospheric boundary layer. Cambridge atmospheric and space science series.

Grossman RL, Nimal G. 1995. Moisture flux and mixing processes in the daytime continental convective boundary layer. J. Geophys. Res. 100: 25665-25674.

Kalapureddy MC, Lothon M, Campistron B, Lohou F, Said F. 2009. Wind profiler observations of the African Easterly Jet and its interactions with the boundary layer and Saharan heat low. $Q . J$. R. Meteorol. Soc. 136(s1): 77-91

Kim S-W, Park S-U, Pino D, Vilà-Guerau de Arellano J. 2006. Parameterization of entrainment in a sheared convective boundary layer using a first-order jump model. Boundary-Layer Meteorol. 120: $445-475$.

Lavaysse C, Flamant C, Janicot S, Parker DJ, Lafore J-P, Sultan B, Pelon J. 2009. Seasonal evolution of the West African Heat Low: A climatological perspective. Clim. Dyn. In press. DOI: 10.1007/s00382-009-0553-4.

Lee Y, Campistron B, Kim KE. 2007. 'Preliminary results obtained from the 3D analysis of the AMMA wind-profiler radar synoptic network'. Second International AMMA Conference, Karlsruhe, 26-30 November 2007.

Lenschow DH, Stephens PL. 1980. The role of thermals in the convective boundary layer. Boundary-Layer Meteorol. 19: 509-532. 
Lenschow DH, Mann J, Kristensen L. 1994. How long is long enough when measuring fluxes and other turbulence statistics? J. Atmos. Oceanic Technol. 11: 661-673.

Lenschow DH, Krummel PB, Siems ST. 1999. Measuring entrainment, divergence and vorticity on the mesoscale from aircraft. J. Atmos. Oceanic Technol. 16: 1384-1400.

Lilly DK. 1968. Models of cloudy-topped mixed layers under a strong inversion. Q. J. R. Meteorol. Soc. 94: 292-309.

Lohou F, Said F, Lothon M, Durand P, Serça D. 2009. Planetary boundary-layer processes signatures on turbulent characteristics and heat fluxes at surface. Boundary-Layer Meteorol. submitted

Lothon M, Couvreux F, Donier S, Guichard F, Lacarrère P, Noilhan J, Said F. 2007. Impact of the coherent eddies on airborne measurements of vertical turbulent fluxes. Boundary-Layer Meteorol. 124: 425-447.

Lothon M, Said F, Lohou F, Campistron B. 2008. Observation of the diurnal cycle in the low troposphere of West Africa. Mon. Weather Rev. 136: 3477-3500.

Lothon M, Lenschow DH, Mayor S. 2009. Doppler lidar measurements of vertical velocity spectra in the convective boundary layer. Boundary-Layer Meteorol. DOI: 10.1007/s10546-009-9398-y.

Mahrt L, Lenschow DH. 1976. Growth dynamics of the convective mixed layer. J. Atmos. Sci. 33: 41-51.

Miao Q, Geerts B. 2006. Vertical velocity and buoyancy characteristics of coherent echo plumes in the convective boundary layer, detected by a profiling airborne radar. J. Appl. Meteorol. Climatol. 45: $838-855$.

Miller J, Thomas A, Bannon P. 2001. A shallow-water model of the diurnal dryline. J. Atmos. Sci. 58: 3508-3524.

Nicholls S. 1989. The structure of radiatively driven convection in stratocumulus. Q. J. R. Meteorol. Soc. 115: 487-510.

Parker DJ, Burton RR, Diongue-Niang A, Ellis RJ, Felton MA, Taylor CM, Thorncroft CD, Bessemoulin P, Tompkins A. 2005. The diurnal cycle of the West African Monsoon circulation. $Q$. $J$. R. Meteorol. Soc. 131: 2839-2860.

Peyrillé P. 2005. 'Etude idéalisée de la mousson ouest-africaine à partir d'un modèle numérique bi-dimensionnel'. $\mathrm{PhD}$ thesis, Université Toulouse III, France.
Peyrillé P, Lafore J-P. 2007. An idealized two-dimensional framework to study the West African Monsoon. Part II: Large-scale advection and the diurnal cycle. J. Atmos. Sci. 64: 2783-2803.

Pino D. 2006. Role of shear and the inversion strength during sunset turbulence over land: Characteristic length scales. Boundary-Layer Meteorol. 121: 537-556.

Redelsperger J, Thorncroft C, Diedhiou A, Lebel T, Parker DJ, Polcher J. 2006. African Monsoon Multidisciplinary Analysis (AMMA): An international research project and field campaign. Bull. Amer. Meteorol. Soc. 87: 1739-1746.

Roca R, Lafore J-P, Piriou C, Redelsperger J-L. 2005. Extratropical dry-air intrusions into the West African monsoon midtroposphere: An important factor for the convective activity over the Sahel. $J$. Atmos. Sci. 62: 390-407.

Saïd F, Canut G, Durand P, Lohou F, Lothon M. 2009. Seasonal evolution of the boundary-layer turbulence measured by aircraft during the AMMA 2006 Special Observation Period. Q. J. R Meteorol. Soc. 136(s1): 47-65

Stevens B. 2002. Entrainment in stratocumulus-topped mixed layers. Q. J. R. Meteorol. Soc. 128: 2663-2690.

Stevens B, Lenschow DH, Faloona I, Moeng C-H, Lilly DK, Blomquist B, Vali G, Bandy A, Campos T, Gerber H, Haimov S, Morley B, Thornton D. 2003. On entrainment rates in nocturnal marine stratocumulus. Q. J. R. Meteorol. Soc. 129: 3469-3492.

Sultan B, Janicot S. 2000. Abrupt shift of the ITCZ over West Africa. Geophys. Res. Lett. 27: 3353-3356.

Tennekes H. 1973. A model for the dynamics of the inversion above a convective boundary layer. J. Atmos. Sci. 30: 538-567.

Träumner K, Wieser A, Kottmeier C, Corsmeier U. 2009. 'Shorttime fluctuations of the convective boundary-layer height and entrainment processes observed with Doppler lidar'. Proceedings of the 4th Symposium on Lidar Atmospheric Applications, Phoenix, Arizona. Amer. Meteorol. Soc: Boston.

Weckwerth TM, Parsons DB, Koch SE, Moore JA, Demoz BB, Flamant C, Geers B, Wang J, Feltz WF. 2004. An overview of the international $\mathrm{H}_{2} \mathrm{O}$ project (IHOP_2002) and some preliminary highlights. Bull. Amer. Meteorol. Soc. 85: 253-277. 